\section{Carbonate mineral detection by variable atmosphere differential thermal analysis}

GREATLY improved detection limits for the presence of anhydrous carbonate minerals in mixtures with other types of minerals can be obtained by variable atmosphere differential thermal analysis (DTA) using dynamic furnace atmospheres of $\mathrm{CO}_{2}$ (flow rate $\left.100 \mathrm{ml} \mathrm{min}^{-1}\right)^{1}$. Details will be published elsewhere ${ }^{2.3}$ (see ref. 1 for details of the Du Pont unit and conditions of analysis). These carbonates fall into two groups; those which decompose in $\mathrm{CO}_{2}$ with single, or multiple ${ }^{4}$ endothermic dissociation reactions liberating $\mathrm{CO}_{2}$. The first group contains, calcite $\mathrm{CaCO}_{3}$, magnesite $\mathrm{MgCO}_{3}$, smithsonite $\mathrm{ZnCO}_{3}$, and siderite $\mathrm{FeCO}_{3}$ (ref. 5); while the second includes dolomite $\mathrm{CaMg}\left(\mathrm{CO}_{3}\right)_{2}$, ankerite $\mathrm{Ca}(\mathrm{MgFe})\left(\mathrm{CO}_{3}\right)_{2}$ and cerussite $\mathrm{PbCO}_{3}$ (ref. 4). Here calcite and dolomite are taken as typical examples and their behaviour described.

In conditions of dynamic $\mathrm{CO}_{2}$ compared with static air, the single endothermic peaks of group one members show several important DTA curve modifications (Fig. $1 b$ and $($ ): peaks become narrower, and more sharply defined with much increased peak heights; the complete peaks, including initial, peak and final temperatures, move up scale to occur at considerably higher temperatures.

The multiple endothermic peaked second group behave differently in the same conditions (Fig. $1 d$ and $f$ ): the initial peak becomes displaced down scale ${ }^{2.0}$ (sometimes, due to crystallinity and equipment, for low concentrations, the known fall in peak temperatures due to dilution when determined in air ${ }^{6}$ and their relative stability in dynamic $\mathrm{CO}_{2}$ may cause both dolomite peaks to appear up scale from the fused composite peak representing them in air (Fig. $1 d$ and $f)$ ). The higher temperature peak (dolomite) or peaks (ankerite) move up scale to occur at higher temperatures with considerably increased and decreased peak heights and widths respectively; markedly increased peak sep-

Fig. 1 Differential thermal analysis curves of calcite and dolomite obtained from artificial mixtures of $a, 0.5^{\circ}$ calcite: $h .6 \%$ calcite: $c$. $6^{\circ} \%$ calcite: $d, 6^{\circ}{ }_{0}$ dolomite: $c .0 .5^{\circ}{ }_{0}$ dolomite: $f .6^{\circ}{ }^{\circ}$ dolomite by weight with calcined alumina. Determinations being made in furnace atmosphere conditions of static air (dotted line) or dynamic carbon dioxide (solid line). The much improved peak definition. resolution and detection limits are clearly shown by the curves determined in dynamic carbon dioxide.

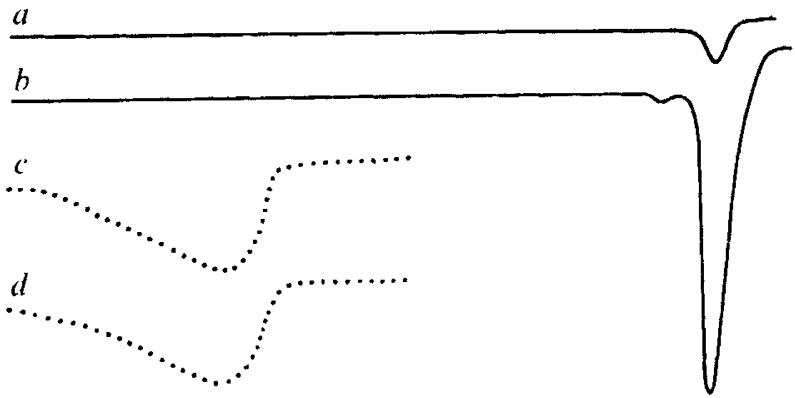

$e^{2}$

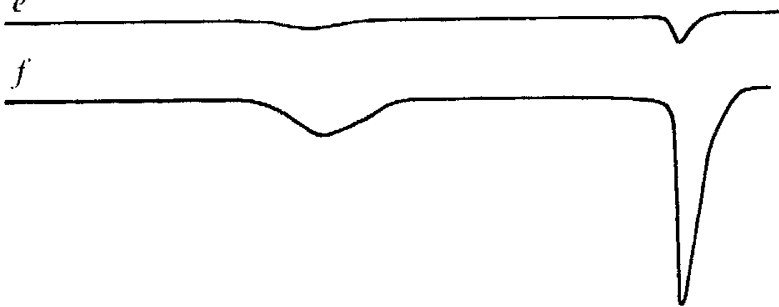

\begin{tabular}{cccccc}
1 & 1 & 1 & 1 & 1 & 1 \\
\hline & 700 & & 1,000 \\
Temperature ( C) & & &
\end{tabular}

aration and definition results. Individual peaks remain recognisable down to the limits of detection (see Fig. 1e) and do not, with progressive content dilution coalesce into the single broad similar (difficult to identify) features which typically result from determinations in air (compare Fig. $1 d$ and $f$ ). The size of the now clearly resolved middle endothermic peak of ankerite. varies with iron content ${ }^{2}$.

The DTA of such carbonates in these conditions enables their greatly improved detection down to contents in the order of $0.25 \%$, the identification of members of the dolomite-ferroan dolomite-ankerite series ${ }^{2}$ and the detection of "iron carbonate components, present either as siderite or ankerite-ferroan dolomite with detection limits and content evaluations ${ }^{2}$ which seem considerably superior to those obtainable by routinely available $X$-ray diffraction data, which emphasises the potential of DTA in this aspect of determinative mineralogy.

I thank the University of Bristol (Geology) and the Macaulay Institute for Soil Research (Pedology) for the opportunity to undertake this work during the tenure of a visiting professorship.

S. ST J. WARNE

Department of Geologl:

The University of Nencastle.

Shortland, Nen South Wales 2308

Australia

Reccived 28 July: accepted 19 August 1977

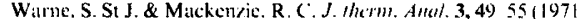

Warne. S. Si J. 5 hh Im. (onfed. hicrm. Anth. Japan (1977).

Warne. S. St J. \& Mitchell. B. D. Bi. J. Sail Sci. (submitted

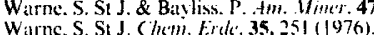

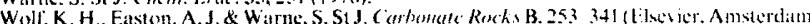
$1967)$

\section{$\Delta^{2}$-Sterenes as diagenetic intermediates in sediments}

A SMALL fraction of the sterols derived from living organisms is found intact or partially degraded in the geological environment. Seawater and many recent or relatively immature older sediments contain unaltered, or only slightly altered sterols ${ }^{1}{ }^{8}$, whereas in older sediments and petroleum these compounds have usually been transformed by redox reactions into their saturated (steranes) or partially aromatised counterparts ${ }^{9-12}$. Due to the high stability of the steroid skeleton, products derived from steroids can be detected in consolidated sediments far into an advanced stage of maturation. We have examined 11 recent sediments and suggest here that the $\Delta^{2}$-sterenes which they contain are degradation intermediates of the precursor sterols.

The characterisation of degradation intermediates. for example. unsaturated hydrocarbons, can bring a better understanding of the nature of the evolution pathways undergone by the sterols in the sedimentary environment, as well as useful information on the stages of evolution at which various degradation reactions take place $^{13}$. Mono- and di-unsaturated steroid alkenes have been tentatively detected in various sediments, but these compounds have not been conclusively identified ${ }^{14-16}$.

We have now studied the unsaturated hydrocarbon fraction of 11 recent sediments - five from the sea of Norway, one from the Baltic sea, two from the vicinity of the Amazon estuary, one from the Cariaco Trench near Venezuela and two continental muds from the immediate vicinity of Strasbourg. The samples were frozen and freeze-dried immediately after collection. The dry samples were then extracted with freshly-distilled chloroform in a Soxhlet apparatus or under ultrasonics. When necessary the total extracts were desulphurised on active copper and separated by thinlayer chromatography (TLC) on $\mathrm{SiO}_{2}$ with hexane elution. The unsaturated hydrocarbons $(10-20 \%$ of the total saturated + unsaturated hydrocarbons) were further separated by $\mathrm{Ag}^{+} / \mathrm{SiO}_{2}$ TLC with hexane elution yielding 1-2 p.p.m. by weight based on 